\title{
Atributos químicos, físicos e mineralogia de Latossolos e sua relação com a paisagem no oeste do Paraná
}

\section{Chemical and phisycal atributes and mineralogy in Latossols (Oxisols) and their relation with the landscape in the west of Paraná}

\author{
Luciane Marcolin $^{1 *} \varangle$ (D),Marcia Regina Calegari² $₫$ (iD) \\ 1Programa de Pós-Graduação em Geografia, Centro de Ciências da Terra, Universidade \\ Federal do Paraná, Curitiba, Paraná, Brasil \\ ${ }^{2}$ Colegiado de Geografia, Centro de Ciências Humanas, Educação e Letras, Universidade \\ Estadual do Oeste do Paraná, Marechal Cândido Rondon, Paraná, Brasil \\ E-mail: marciareg_calegari@hotmail.com \\ *E-mail para correspondência: lucianemarcolin@hotmail.com
}

Recebido (Received): 28/05/2019 Aceito (Accepted):07/11/2019

\begin{abstract}
Resumo: Os solos fazem parte da paisagem e podem inferir sobre sua evolução. Em áreas de relevos mais estáveis é possível encontrar solos espessos e muito evoluídos pedogeneticamente, pois a natureza e a paisagem local permitiram tal evolução. Os solos guardam registros da sua evolução e através de seus atributos é possível inferir sobre seu atual estágio evolutivo. Com esse intuito foi realizado um estudo pedológico para investigar dois perfis de Latossolos em Marechal Cândido Rondon-Pr. A escolha desta classe de solos é justificada por ser a mais representativa da região e haver grande carência de estudos sobre a caracterização mineralógica e evolutiva desses solos na região oeste do Paraná. Foi estudado um perfil de alteração completo e um perfil de até dois metros de profundidade (seção de controle) visando obter uma primeira aproximação do nível de evolução da cobertura pedológica e os processos pedogenéticos atuantes. Neste trabalho foram realizadas análises químicas, físicas e mineralógicas, onde os resultados confirmam a natureza caulinítica dos Latossolos Vermelhos. A assembleia mineralógica é composta predominantemente por minerais 1:1 (Caulinita), mas também apresenta mineral 2:1 (Vermiculita com hidroxi-entrecamadas). Os resultados indicam que predominou o processo de monossialitização com hidrólise parcial ao longo da pedogênese, em concordância a paisagem local e ambiente de formação sob clima subtropical (muito intemperizado).
\end{abstract}

Palavras-chave: Pedogênese; Latossolo; Paisagem; Oeste do Paraná.

Abstract: The soils are part of the landscape and they can infer about their evolution. On areas with more stables reliefs is possible to find deep and pedogenetically evolved soils, because the nature and local landscape allowed such evolution. Soil keeps records about its evolution and through the attributes is possible to infer about its current evolution stage. On this purpose, it was performed a pedological study to investigate two Latossolos (Oxisols)from Marechal CândidoRondon, Paraná, Brazil. The choice of this soil classes is justified by being the most representative on the region and being great studies shortage about the mineralogical description and evolutional around these soils on the west of Paraná, Brazil. So it was studied one complete alteration soil profile and another one with until two meters deep (control section) in order to obtain a first approximation of the evolution level from pedological covering and the acting pedogenetical processes. It was performed in this work a chemical, physical and mineralogical analysis, which one the results confirmed the kaolinite nature those Latosols (Oxisol). The mineralogical assembly is, predominantly, composed of 1:1 (kaolinite), but also has minerals 2:1 (vermiculite with hydroxylinterlayered). The results indicate that was predominat process monossialitization with partial hydrolysis along pedogenesis, in accordance the local landscape and environment formation under subtropical climate (very weathered).

Keywords: Pedogenesis;Latossolo (Oxisol); Landscape; West of Paraná. 


\section{Introdução}

O Solo é um recurso natural essencial e um grande integrador entre os processos naturais e antrópicos e pode preservar registros da história geológica, geomorfológica, climática, biológica e humana de uma paisagem (DENT et al., 2007), que está em constante transformação, sofrendo alterações em suas características primárias. Em regiões de climas tropicais e subtropicais como no sul do Brasil, as transformações e a evolução da paisagem ocorrem de maneira acentuada devido ao intemperismo químico, que promove um maior desgaste da superfície através de processos desencadeados e potencializados pelas altas temperaturas e precipitação (TRICART, 1972; BECKER et al., 2012).

O modelado do relevo se diferencia por apresentar formas variadas, decorrentes da atuação de diferentes climas ao longo do tempo. Os solos acompanham as diferentes formas de relevo que interferem na geografia do solo. Em áreas de relevos mais estáveis, de formações mais planas é possível encontrar solos maduros, espessos e muito evoluídos pedogeneticamente, pois a natureza e a paisagem local permitiram tal evolução.

Queiroz Neto (2000) considera que a relação morfogênese/pedogênese pode influenciar e/ou refletir a relação entre os solos (grau de intemperismo baseados nos teores de argila e perda de bases) e as superfícies de idades diferentes. Quanto maior o grau de pedogênese, maior o grau de alteração dos minerais primários em argilominerais e maiores são as perdas de bases, pois proporcionam o intemperismo e a pedogênese dos solos. Vários processos são ocasionados pelo processo de intemperismo (FONTES, 2012). Em regiões de climas tropicais e subtropicais o processo mais acentuado de ocorrência é a hidrólise, permitindo a evolução pedogeoquímica dos solos em estado de monossialitização, biassilitização e/ou alitização (MELFI; PEDRO, 1977).

Os Latossolos são, em geral, solos com alto grau de intemperização, sendo muito evoluídos pedogeneticamente. Apresentam baixa capacidade de troca de cátions da fração argila $\left(>17 \mathrm{cmol}_{\mathrm{c}} \mathrm{Kg}^{-1}\right) \mathrm{e}$ variam desde solos predominantemente cauliníticos, com valores de Ki mais altos (2,0-2,2) até solos oxídicos com valores de Ki muito baixo (EMBRAPA, 2018).

A relação solo paisagem tem a finidade com a discussão morfogênese/pedogênese, onde a estabilidade tectônica, o material de origem e clima no local estudado favorecem o predomínio da pedogênese, tornando o relevo uma unidade de paisagem com características relacionadas entre si e sendo refletidas no solo de maneira homogênea e muito representativa do ambiente de formação.

Estudos em áreas de superfícies geomórficas, consideradas como porções de terra definidas no tempo e espaço, com limites geográficos e formada por um ou mais agentes num determinado período de tempo (DANIELS et al., 1971) foram realizadas em diferentes locais e apontam para a evolução e formação de extensas áreas, submetidas a diferentes processos, associados a degradação e agradação de material pedológico. Neste sentido, este estudo teve como objetivo caracterizar física, química e mineralógicamente dois perfis de Latossolos, visando obter uma primeira aproximação do nível de evolução da cobertura pedológica e os processos pedogenéticos atuantes na área do estudo.

\section{Materiais e métodos}

\section{1. Área de estudo}

Os perfis de solo selecionados para este estudo, representativos da ordem dos Latossolos, estão localizados no município de Marechal Cândido Rondon (Figura 1), mesorregião Oeste do Paraná. O clima da região é o Subtropical Úmido Mesotérmico (verões quentes e pouca ocorrência de geadas e concentração de chuvas no verão). Os solos estudados ocorrem em zona de clima subtropical, onde o intemperismo químico é intenso, favorecendo a ocorrência de processos intempéricos e mineralógicos também intensos (CAVIGLIONE et al., 2000).

Na mesorregião do Oeste do Paraná aparecem diferentes subunidades morfoesculturais, que se diferem pelo entalhamento da rede de drenagem, influenciando na dissecação do relevo, diferentes altitudes e diferentes unidades geológicas.

As subunidades em que estão inseridos os perfis Latossólicos estudados pertencem, segundo a divisão geomorfológica da Mineropar (2006), as subunidades de Planalto de Cascavel e Planalto de Foz do Iguaçu (MAGALHÃES, 2013) (Figura 2). 


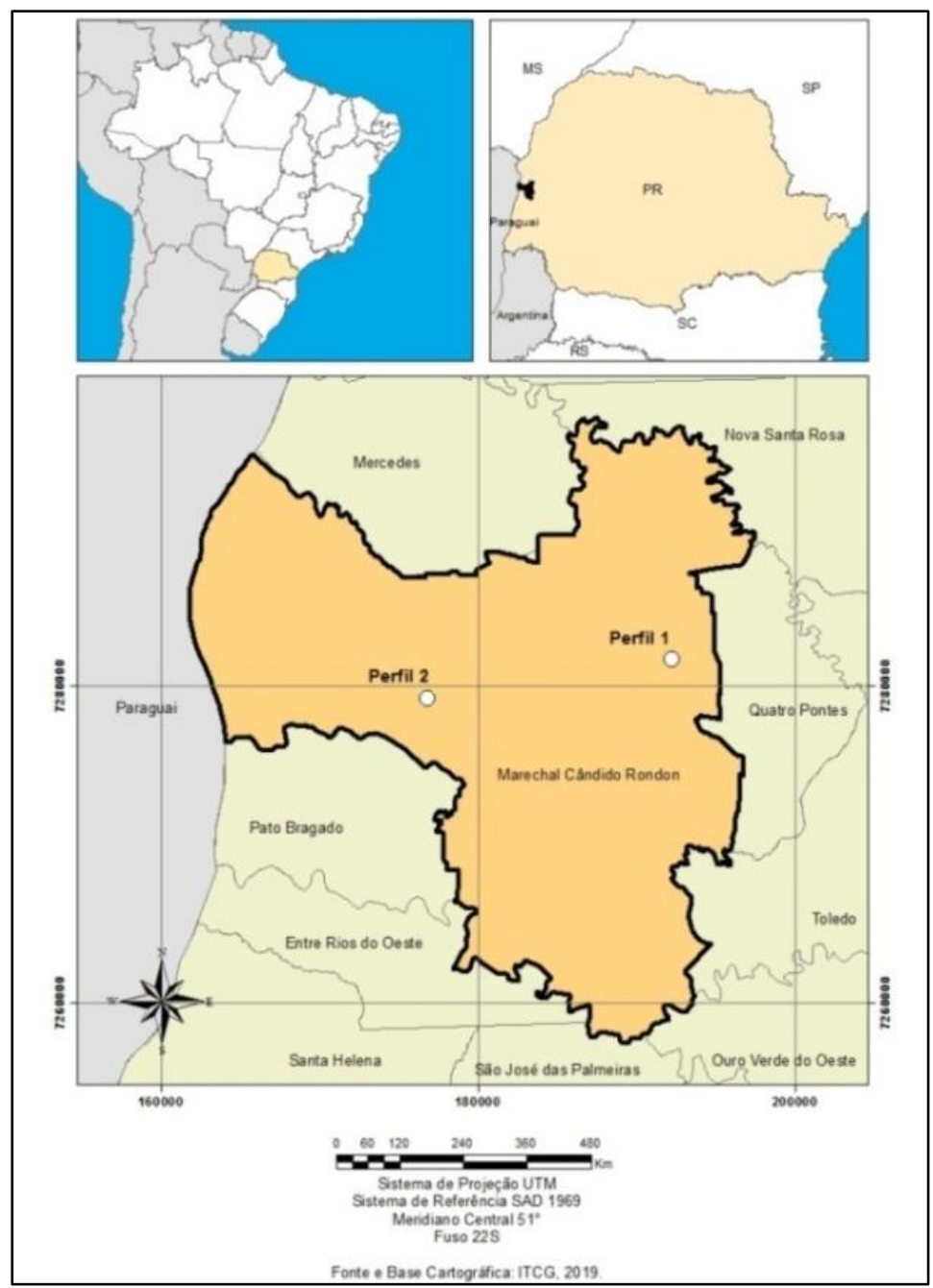

Figura 1: Localização das áreas de estudo: P1 (Perfil 1) e P2 (Perfil2) em Marechal Cândido Rondon- Pr. Fonte: Elaborado pelas autoras.

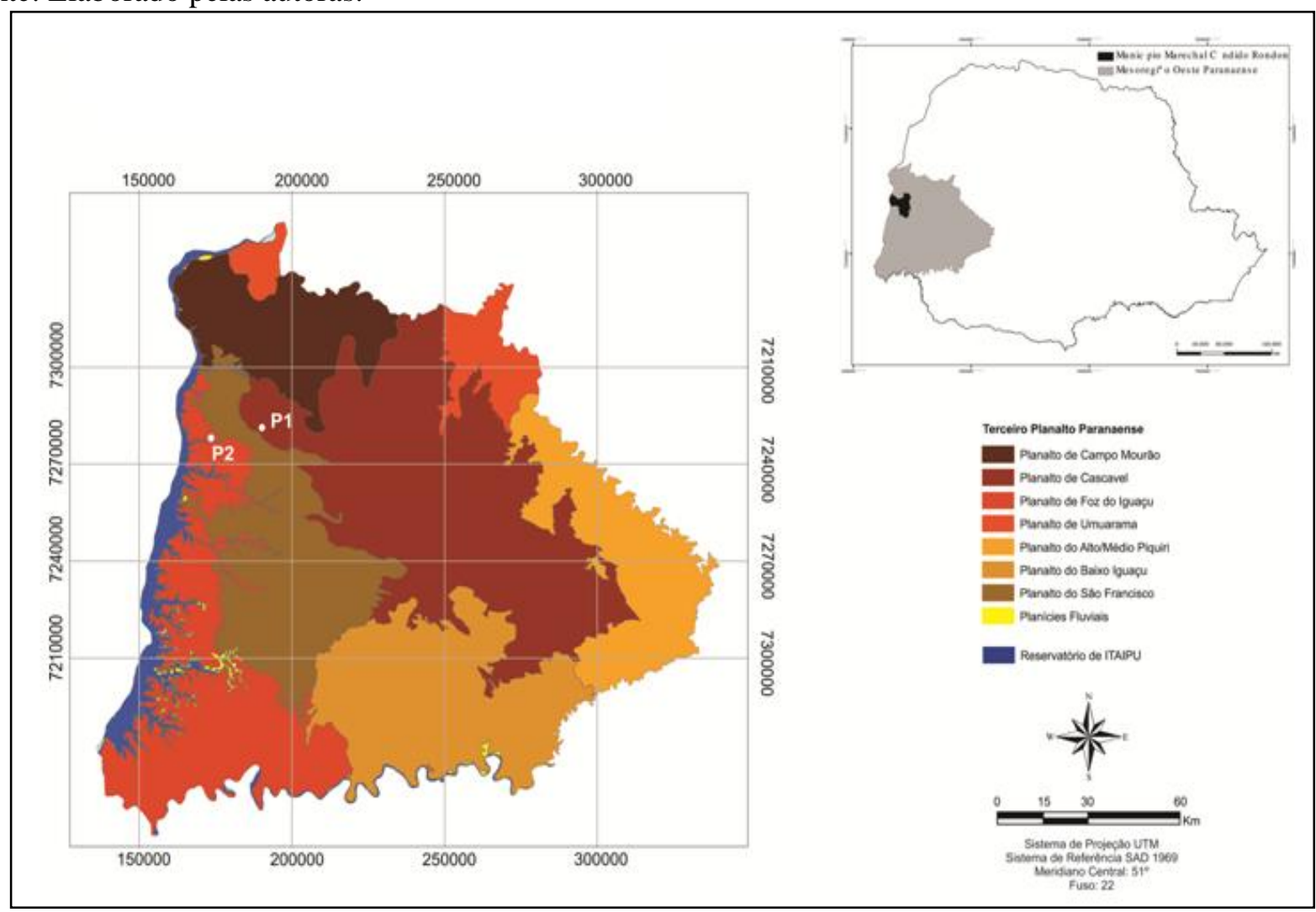

Figura 2: Subunidades Geomorfológicas do Oeste Paranaense. Mineropar (2006). Fonte: Elaborado pelas autoras. 
As rochas ígneas que predominam na região de Marechal Cândido Rondon são compostas por basaltos maciços e amigdalóides, afaníticos, cinzentos a pretos. Essas rochas são classificadas como de baixa vulnerabilidade ambiental, tendo alta resistência ao intemperismo e a erosão (MINEROPAR, 2006).

Relacionadas às rochas basálticas na região estudada predominam o Latossolo Vermelho Eutroférrico profundo em locais de relevo mais plano e nos locais de relevo mais ondulado, declividades um pouco maiores ocorrem Nitossolo Vermelho Eutroférrico. Já em áreas com declividades mais acentuadas são encontrados os Neossolos Litólicos (MORESCO, 2007) (Figura 3).

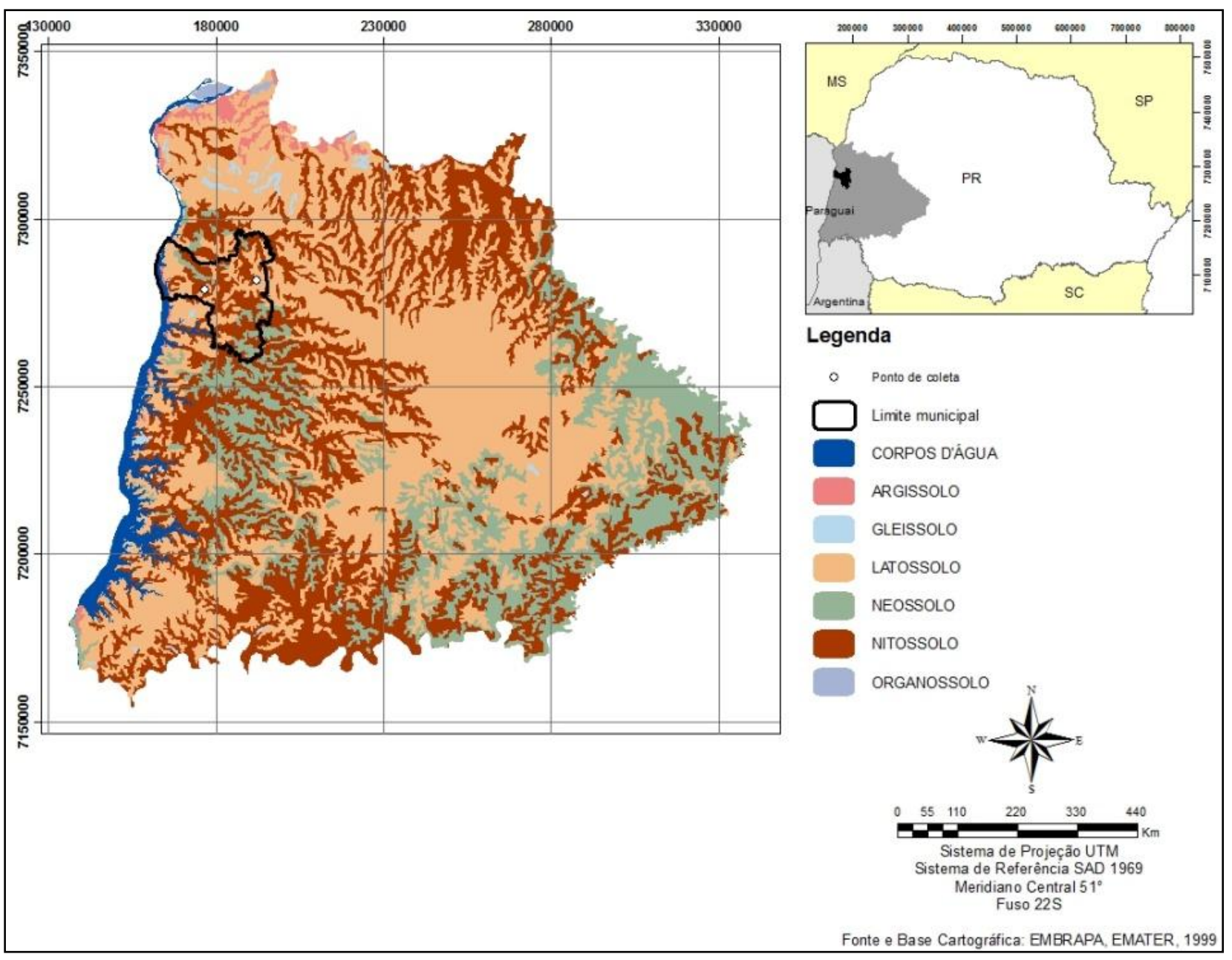

Figura 3: Ocorrência de solos na região Oeste do Paraná. Fonte: Elaborado pelas autoras.

\subsection{Seleção de perfis de solo e descrição morfológica}

Foram selecionados 2 perfis de solo. O perfil 1 representa uma seção de controle de dois metros de profundidade, localizado à $24^{\circ} 33^{\prime} 01,88^{\prime}$ ' Lat.S e 54 $03^{\prime} 14,93^{\prime \prime}$ Long. W, na Subunidade Geomórfica Planalto de Cascavel (SANTOS et al., 2006), a 427 metros de altitude, sob floresta, em uma reserva particular dentro no núcleo urbano. O perfil 2 representa um perfil de alteração e está geograficamente localizado a $24^{\circ} 34^{\prime} 31,7^{\prime}$ ' S e $54^{\circ} 12^{\prime} 17,7^{\prime}$ ' W, na Subunidade Planalto de Foz do Iguaçu, a 274 metros de altitude, em área de agricultura mecanizada.

A descrição morfológica dos perfis foi realizada em campo conforme Santos et al. (2015) que consiste na descrição da transição entre horizontes pedológicos, sua profundidade e espessura, cor, textura, estrutura e consistência (seca, úmida e molhada) dos horizontes pedogenéticos. Foram realizadas coletas de amostras por horizontes para análises químicas, físicas de rotina e mineralógicas. Os resultados foram utilizados para a classificação dos solos até o quarto nível categórico, conforme o SIBCS (2018). 


\subsection{Análises físicas}

As análises físicas foram realizadas conforme procedimentos descritos em Embrapa (1997). Foram realizadas as análises granulométricas, pelo método da pipeta; argila dispersa em água; densidade do solo pelo método do anel volumétrico- Kopecky; densidade de partículas pelo método do balão volumétrico. As análises foram realizadas no laboratório de Física do Solo do departamento de Agronomia da Universidade Estadual do Oeste do Paraná- Campus Marechal Cândido Rondon.

\subsection{Análises químicas}

As análises químicas de rotina foram realizadas para caracterização e classificação dos solos. São elas: Cálcio e Magnésio $\left(\mathrm{Ca}^{2+}+\mathrm{Mg}^{2+}\right)$, Potássio $\left(\mathrm{K}^{+}\right)$, Acidez potencial $(\mathrm{H}+\mathrm{Al})$ (tampão SMP) e pH (Acidez ativa) em $\mathrm{CaCl}_{2}$, capacidade de Troca de Cátions (CTC) foi determinada através dos valores da soma de bases $(\mathrm{Ca}+\mathrm{Mg}+\mathrm{K})$ e da acidez potencial $(\mathrm{H}+\mathrm{Al})$. $\mathrm{O}$ teor de matéria orgânica foi determinado conforme o método Walkley e Black (1934) (CAMARGO et al. 2009).

Foi realizado também o ataque sulfúrico (EMBRAPA, 1997). para determinação dos óxidos de Ferro $\left(\mathrm{Fe}_{2} \mathrm{O}_{3}\right)$, Silício $\left(\mathrm{SiO}_{2}\right)$, Alumínio $\left(\mathrm{Al}_{2} \mathrm{O}_{3}\right)$ Titânio $\left(\mathrm{TiO}_{2}\right)$ e Manganês $(\mathrm{MnO})$ e cálculo das relações moleculares $\mathrm{Ki}\left(\mathrm{SiO}_{2} / \mathrm{Al}_{2} \mathrm{O}_{3}\right)$ e $\mathrm{Kr}\left(\mathrm{SiO}_{2} / \mathrm{Al}_{2} \mathrm{O}_{3}+\mathrm{Fe}_{2} \mathrm{O}_{3}\right)$. As análises foram realizadas no Laboratório de Análise de Solos da Escola Superior de Agricultura Luiz de Queiroz - ESALQ/USP.

\subsection{Análises mineralógicas}

Foi realizada a difratometria de raios X (DRX) nas amostras de cada horizonte de ambos os perfis. A análise foi realizada na Universidade Federal de Viçosa- MG, Departamento de solos, nas frações argila $(<$ $0,002 \mathrm{~mm})$ e silte $(0,002 \mathrm{~mm}-0,050 \mathrm{~mm})$. Materiais de granulometria mais grossa foram moídos e passados por peneira de $0,053 \mathrm{~mm}$. A amostra, em estado pastoso ou em suspensão, foi colocada em uma lâmina de vidro de superfície plana, sob a forma de uma fina película e submetida à irradiação por raios-X em uma faixa ampla de ângulos de incidência (intervalo de $2^{\circ}$ a $45^{\circ}$, por exemplo) aquecidas a $550^{\circ} \mathrm{C}$.

Os difratogramas de RX foram interpretados analisando os reflexos minerais pela distância interplanar (d) que cada mineral apresenta. Estas distâncias interplanares são encontradas pela medida do reflexo em ${ }^{\circ} 2 \Theta$. Os atributos dos minerais foram identificados e medidos pela largura a meia altura (LMA) e a área do pico e pela distância interplanar (RESENDE et al., 2005). A identificação dos minerais foi feita de acordo com as distâncias interplanares propostas por Brown e Brindley (1980) e Moore e Reynolds (1989).

\section{Resultados}

\subsection{Atributos macromorfológicos}

O Perfil 1 foi descrito em uma seção de controle de 2 metros de profundidade, sob floresta, sendo, portanto, um perfil de referência devido à preservação dos atributos químicos e físicos naturais dessa classe de solo. Os atributos macromorfológicos dos solos são representados na Tabela 1.

O perfil 1 apresenta sequência de horizontes pedogenéticos A, AB, BA, Bw1 e Bw2 (Tabela 1). Todos os horizontes apresentaram textura muito argilosa (acima de $800 \mathrm{~g} . \mathrm{kg}^{-1}$ de argila). A cor variou entre 10R3/3 e 2,5YR3/3, sendo classificada como bruno-avermelhada. O solo apresentou estrutura em blocos angulares a subangulares, muito plástica e pegajosa e transição entre os horizontes difusa e plana.

O perfil 2 foi classificado como Latossolo Vermelho Eutroférrico típico. É um perfil de alteração, que foi descrito até o contato lítico, em área de uso agrícola. Apresenta sequência de horizontes $\mathrm{Ap}, \mathrm{AB}, \mathrm{BA}, \mathrm{Bw}$ espesso (Bw1; Bw2; Bw3; Bw4) e B/Cr. O perfil apresenta $560 \mathrm{~cm}$ de profundidade. Do horizonte Ap ao horizonte BA apresenta textura argilosa (abaixo de $600 \mathrm{~g}^{\mathrm{kg}} \mathrm{kg}^{-1}$ de argila) e a partir do horizonte Bw1 a textura é muito argilosa. A cor úmida permaneceu constante em 2,5YR 3/4 (bruno-avermelhado escuro). Apresentou estrutura em blocos angulares a subangulares, consistência muito plástica e pegajosa e transição difusa entre horizontes (Tabela 1). 
Tabela 1: Caracterização Morfológica dos perfis de Latossolo Vermelho.

\begin{tabular}{|c|c|c|c|c|c|c|c|c|}
\hline \multirow{2}{*}{$*$ Horiz. } & \multirow{2}{*}{$\begin{array}{l}* \text { Prof. } \\
\text { Cm }\end{array}$} & \multirow{2}{*}{$\begin{array}{c}\text { Cor } \\
\text { úmida }\end{array}$} & Areia & Silte & Argila & \multirow{2}{*}{$\begin{array}{c}\text { Textura } \\
\text { (Embrapa, } \\
\text { 2018) }\end{array}$} & \multirow{2}{*}{ Consistência } & \multirow{2}{*}{ Transição } \\
\hline & & & \multicolumn{3}{|c|}{ 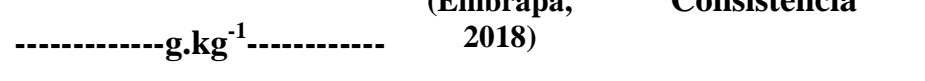 } & & & \\
\hline \multicolumn{9}{|c|}{ Perfil 1- Latossolo Vermelho distrófico úmbrico } \\
\hline Ap & $0-10$ & $2,5 Y R 3 / 4$ & 98,47 & 452,53 & 449 & A & $\begin{array}{c}\text { Plástico; ligeiramente } \\
\text { pegajoso }\end{array}$ & Gradual \\
\hline $\mathrm{AB}$ & $10-25$ & $2,5 Y R 3 / 4$ & 63,37 & 423,63 & 513 & A & $\begin{array}{l}\text { Muito plástico; Muito } \\
\text { pegajoso. }\end{array}$ & Difusa \\
\hline BA & $25-40$ & $2,5 \mathrm{YR} 3 / 4$ & 71,21 & 330,79 & 598 & A & $\begin{array}{l}\text { Muito plástico; Muito } \\
\text { pegajoso. }\end{array}$ & Difusa \\
\hline $\mathrm{Bw}_{1}$ & $40-80$ & $2,5 \mathrm{YR} 3 / 4$ & 71 & 292 & 637 & M A & $\begin{array}{l}\text { Muito plástico; Muito } \\
\text { pegajoso. }\end{array}$ & Difusa \\
\hline $\mathrm{Bw}_{2}$ & $\begin{array}{l}80- \\
150\end{array}$ & $2,5 \mathrm{YR} 3 / 4$ & 71,56 & 293,44 & 635 & M A & $\begin{array}{l}\text { Muito plástico; Muito } \\
\text { pegajoso. }\end{array}$ & Difusa \\
\hline Bw3 & $\begin{array}{l}150- \\
210\end{array}$ & $2,5 \mathrm{YR} 3 / 4$ & 87,06 & 194,94 & 718 & M A & $\begin{array}{l}\text { Ligeiramente } \\
\text { plástico; pegajoso }\end{array}$ & Difusa \\
\hline Bw4 & $\begin{array}{l}210- \\
290\end{array}$ & $2,5 \mathrm{YR} 3 / 4$ & 79,52 & 239,48 & 681 & M A & $\begin{array}{l}\text { Ligeiramente } \\
\text { plástico; pegajoso }\end{array}$ & Difusa \\
\hline $\mathrm{B} / \mathrm{Cr}$ & $\begin{array}{l}290- \\
320\end{array}$ & $2,5 \mathrm{YR} 3 / 4$ & 91,04 & 236,96 & 672 & M A & $\begin{array}{c}\text { Ligeiramente } \\
\text { plástico; pegajoso }\end{array}$ & $\begin{array}{l}\text { Clara à } \\
\text { gradual }\end{array}$ \\
\hline
\end{tabular}

Perfil 2 - Latossolo Vermelho Eutroférrico típico

\begin{tabular}{|c|c|c|c|c|c|c|c|c|}
\hline Ap & $0-10$ & 2,5YR 3/4 & 98,47 & 452,53 & 449 & $\mathrm{~A}$ & $\begin{array}{l}\text { Plástico; ligeiramente } \\
\text { pegajoso }\end{array}$ & Gradual \\
\hline $\mathrm{AB}$ & $10-25$ & 2,5YR 3/4 & 63,37 & 423,63 & 513 & A & $\begin{array}{l}\text { Muito plástico; muito } \\
\text { pegajoso. }\end{array}$ & Difusa \\
\hline BA & $25-40$ & 2,5YR 3/4 & 71,21 & 330,79 & 598 & A & $\begin{array}{l}\text { Muito plástico; muito } \\
\text { pegajoso. }\end{array}$ & Difusa \\
\hline $\mathrm{Bw}_{1}$ & $40-80$ & 2,5YR 3/4 & 71 & 292 & 637 & M A & $\begin{array}{l}\text { Muito plástico; muito } \\
\text { pegajoso. }\end{array}$ & Difusa \\
\hline $\mathrm{Bw}_{2}$ & $\begin{array}{l}80- \\
150\end{array}$ & $2,5 \mathrm{YR} 3 / 4$ & 71,56 & 293,44 & 635 & M A & $\begin{array}{l}\text { Muito plástico; muito } \\
\text { pegajoso. }\end{array}$ & Difusa \\
\hline Bw3 & $\begin{array}{l}150- \\
210\end{array}$ & 2,5YR 3/4 & 87,06 & 194,94 & 718 & M A & $\begin{array}{c}\text { Ligeiramente } \\
\text { plástico; pegajoso }\end{array}$ & Difusa \\
\hline Bw4 & $\begin{array}{l}210- \\
290\end{array}$ & $2,5 Y R$ 3/4 & 79,52 & 239,48 & 681 & M A & $\begin{array}{c}\text { Ligeiramente } \\
\text { plástico; pegajoso }\end{array}$ & Difusa \\
\hline $\mathrm{B} / \mathrm{Cr}$ & $\begin{array}{l}290- \\
320\end{array}$ & $2,5 \mathrm{YR} 3 / 4$ & 91,04 & 236,96 & 672 & M A & $\begin{array}{c}\text { Ligeiramente } \\
\text { plástico; pegajoso }\end{array}$ & $\begin{array}{l}\text { Clara a } \\
\text { gradual }\end{array}$ \\
\hline
\end{tabular}

*Horiz.: horizonte; *Prof.: profundidade*Textura: A= Argilosa; M A= Muito argilosa.

Fonte: Elaborado pelas autoras.

\subsection{Atributos químicos}

De modo geral o perfil de alteração (Perfil 2) apresenta valores desiguais em relação aos atributos químicos do Perfil 1 (Tabela 2). Essas alterações podem refletir a correção e adubação química do solo. Os teores de matéria orgânica do solo (MOS) se assemelham entre os perfis, também apresentam tendência de diminuição em profundidade comum em solos tropicais e subtropicais (BOUTTON, 1996) variando de 28 a 12 g. $\mathrm{kg}^{-1}$ no perfil 1 , e 32 a 8 g. $\mathrm{kg}^{-1}$ no perfil 2. 
Tabela 2: Caracterização química dos perfis de Latossolo Vermelho

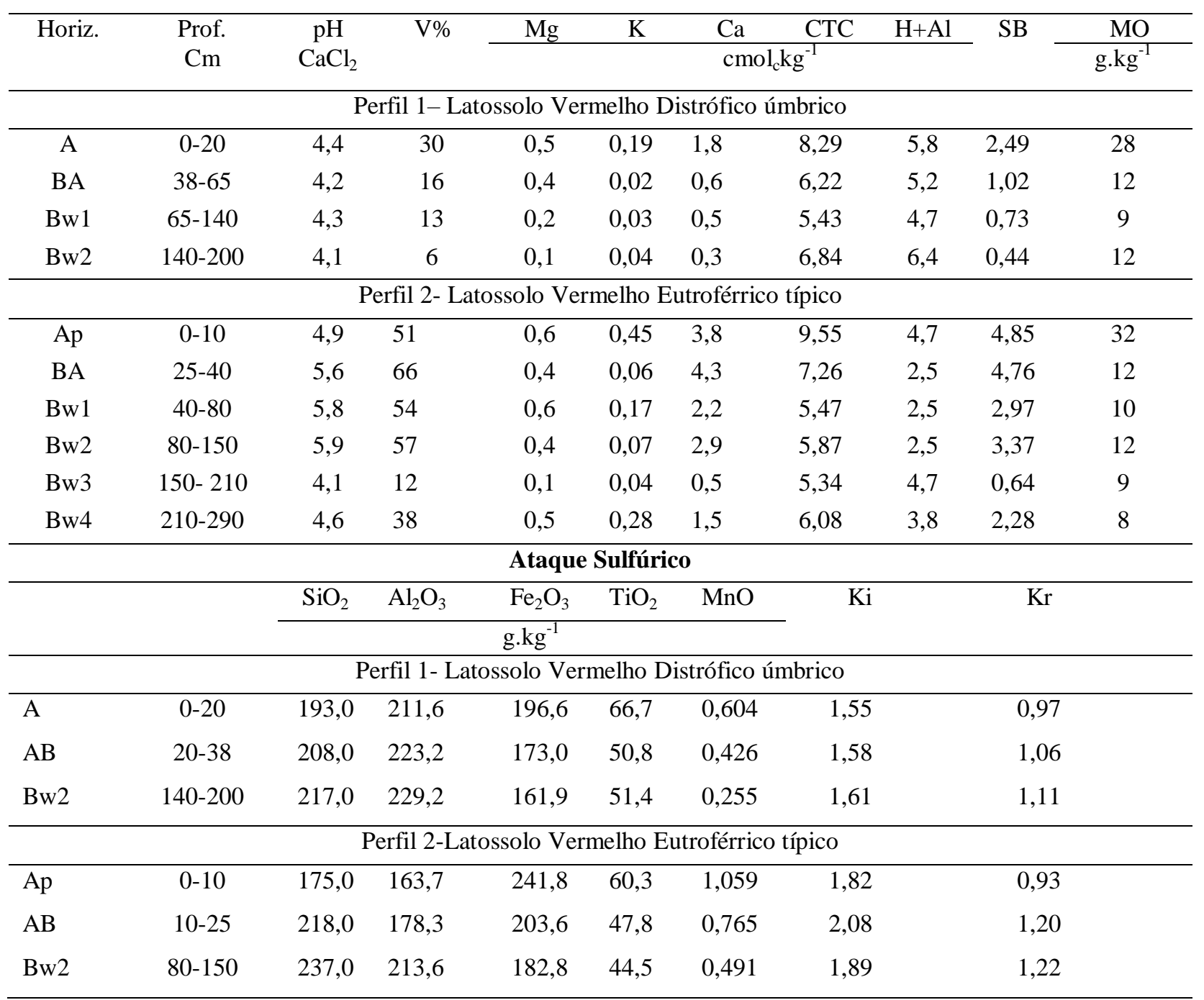

Fonte: Elaborado pelas autoras.

Os valores de $\mathrm{pH}\left(\mathrm{CaCl}_{2}\right)$ revelam acidez moderada (Perfil 2) e ácido (Perfil 1) e a CTC, considerando Embrapa (2018) permitiu classificar o Perfil 1como distrófico (V\% < 50\%) o Perfil 2 como eutrófico (V\% $>50 \%$ ). Este último refletindo o efeito dos insumos neste solo. Observa-se que em ambos os perfis os teores de óxidos de ferro, titânio e manganês apresentam sutis diminuições em profundidade e os óxidos de silício e alumínio apresentam tendência inversa (Tabela 2). Constata-se também que em ambos os perfis os teores de $\mathrm{SiO}_{2}, \mathrm{TiO}_{2}$ e $\mathrm{MnO}$ são bastante parecidos. Verificou-se que, embora haja pequenas variações nos teores de $\mathrm{Al}_{2} \mathrm{O}_{3}$ e $\mathrm{Fe}_{2} \mathrm{O}_{3}$, entre perfis, o conjunto de dados reflete a natureza mais básica do material de origem desses solos, rico em minerais ferromagnesianos.

Os valores para as relações molares $\mathrm{Ki}$ e $\mathrm{Kr}$ foram relativamente baixos, demonstrando avançado estádio de intemperismo desses solos. Valores semelhantes para estas relações foram reportados pela Embrapa (1984) em áreas próximas à Marechal, em Margarida, Toledo e Cascavel

\subsection{Caracterização mineralógica}

Na fração argila de todos os horizontes do perfil Latossolo Vermelho Distrófico úmbrico (Perfil1) e do perfil 2 Latossolo Vermelho Eutroférrico típico foram identificados picos de Caulinita (mineral 1:1), Vermiculita com hidróxi-entrecamada - VHE (mineral 2:1) eGibbsita (hidróxidos de alumínio) (Figuras 4 e 5). 


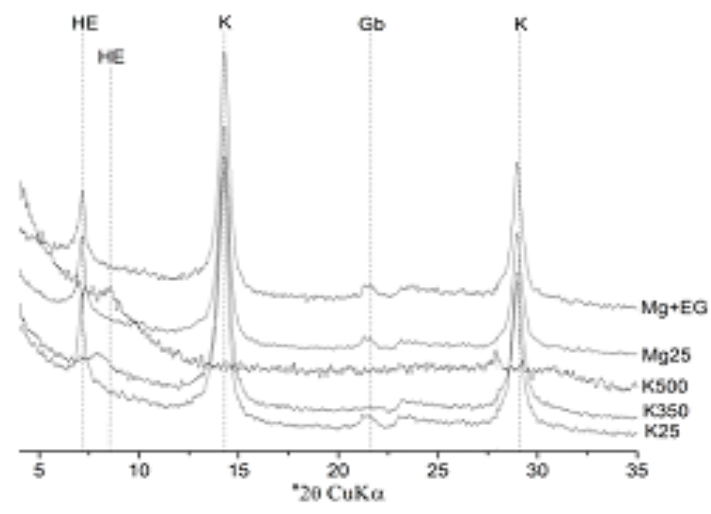

Fração Argila Horizonte BA- Perfil 1

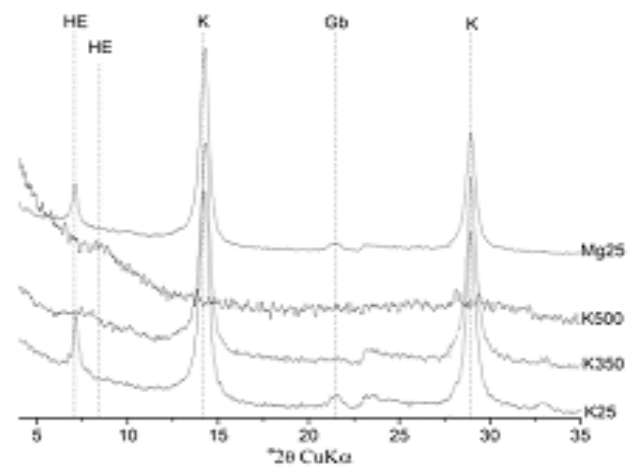

Fração Silte- Perfil 1

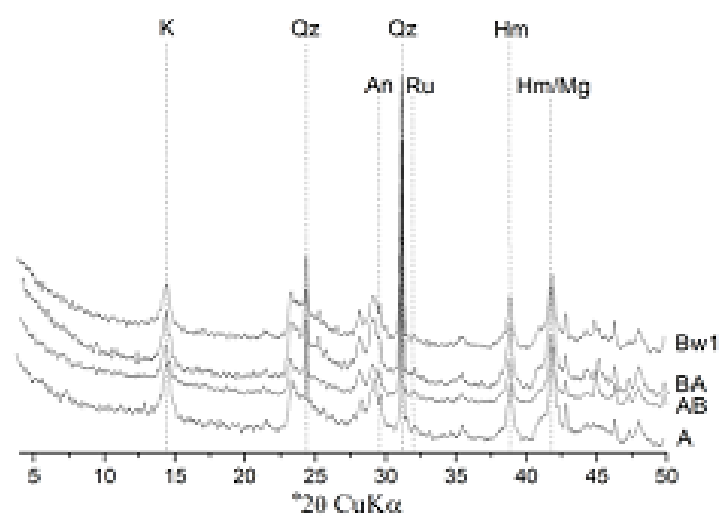

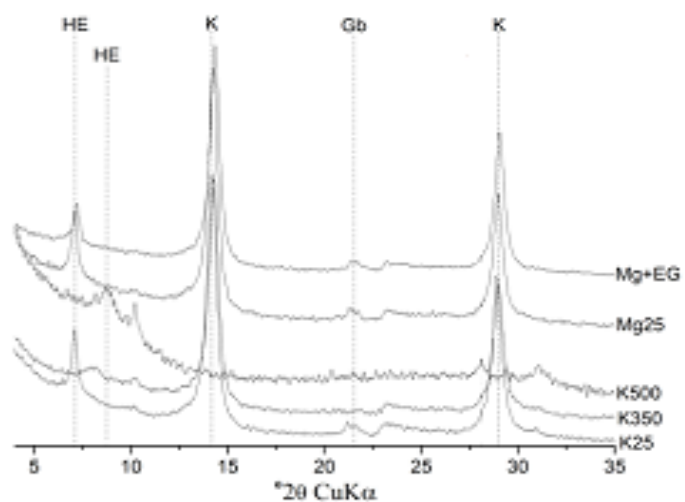

Fração Argila Horizonte Bw1- Perfil 1

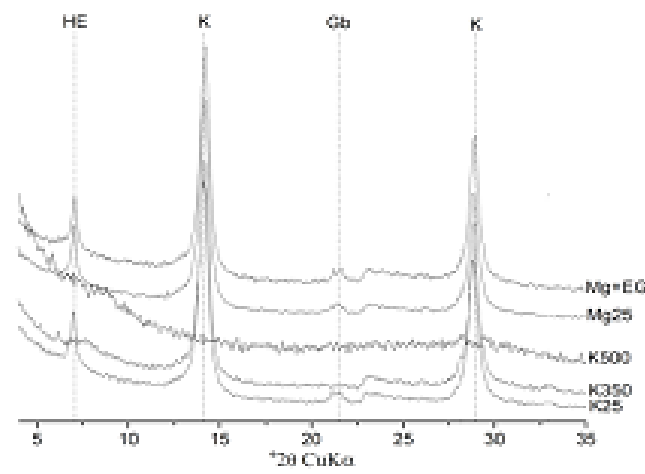

Fração Areia- Perfil1

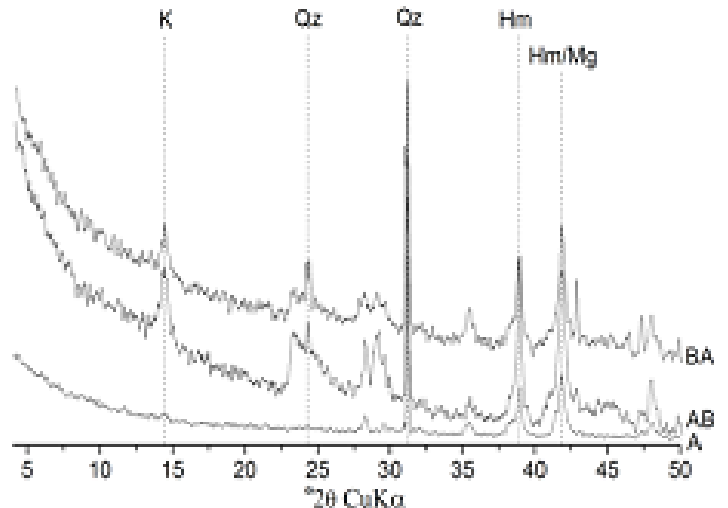

`2Ө Cu Ka: K: Caulinita; Qz: Quartzo; Hm: Hematita; Hm/Mg: Hematita/Magnetita; Na:Anatásio; Ru: Rutílio; Gb: Gibbsita; Na: anidrita; HE: hidroxi- entrecamada.

Figura 4: Mineralogia das Frações Areia, Silte e Argila do Perfil 1. Fonte: Elaborado pelas autoras.

Essa mineralogia, sobretudo a presença de VHE, concorda com a literatura sobre o espaçamento deste argilomineral informando que quando a amostra é saturada com $\mathrm{K}$ ela passa a apresentar valor correspondente a $1,0 \mathrm{~nm}$ se expandindo para $1,4 \mathrm{~nm}$ quando saturadas com $\mathrm{Mg}$, como observado no espaçamento dos reflexos minerais $(1,4 \mathrm{~nm}$ d 001) das amostras analisadas (AZEVEDO; VIDALTORRADO, 2009). O horizonte $\mathrm{B} / \mathrm{Cr}$ do perfil 2 apresenta o mineral VHE (vermiculita hidroxi entrecamadas) com maior largura a meia altura (LMA), indicando, portanto, o menor grau de cristalização mineralógica desse argilomineral (Figura 5). Já nos horizontes A e Bw, em ambos os perfis, apresentam o VHE com menor largura a meia altura indica maior grau de cristalização, como observado por Resende et al. (2005) (Figuras 4 e 5). 
Fração Argila horizonte AB-Perfil 2

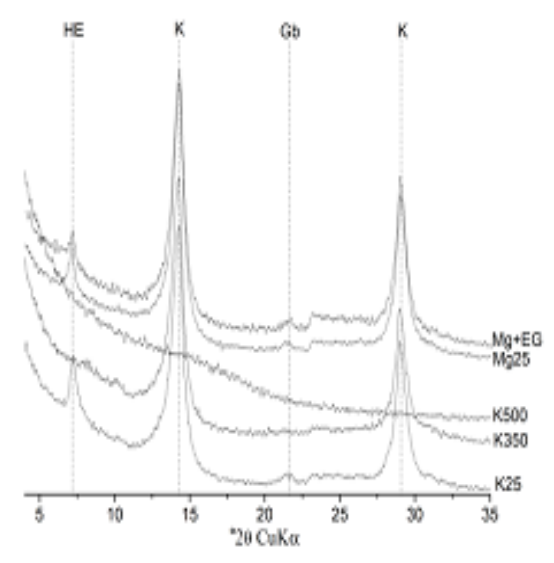

Fração Argila Horizonte Bw1- Perfil 2

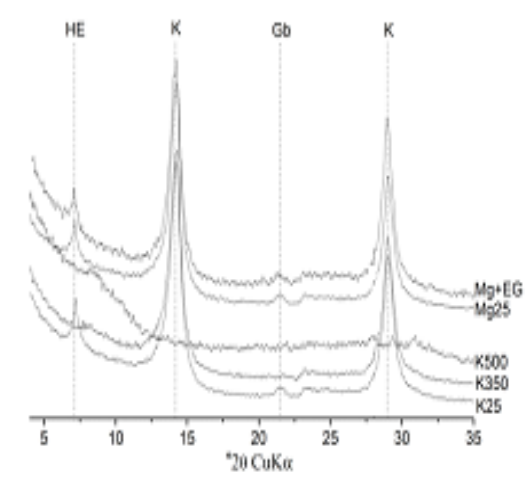

Fração Argila Horizonte Bw4-Perfil 2

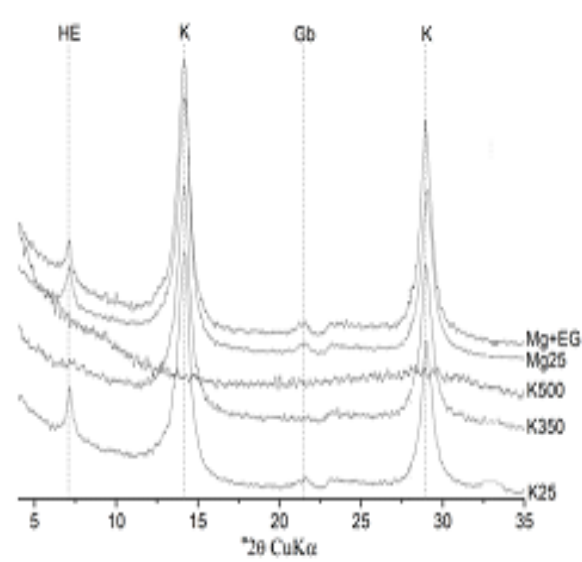

Fração Areia- Perfil2

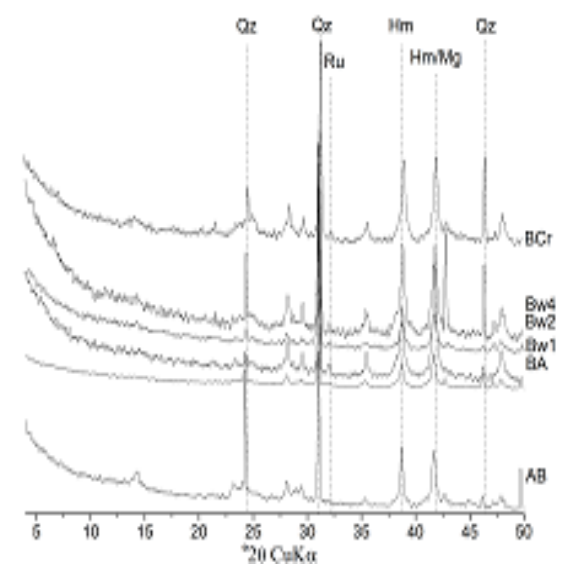

Figura 5: Mineralogia das Frações Areia, Silte e Argila do Perfil 2. Fonte: Elaborado pelas autoras.
$2 \Theta$ Cu Ka: K: Caulinita; Qz: Quartzo; Hm: Hematita; $\mathrm{Hm} / \mathrm{Mg}$ : Hematita/Magnetita; Na:Anatásio; Ru: Rutílio; Gb: Gibbsita; Na: anidrita; HE: hidroxi 
$\mathrm{Na}$ fração areia dos dois perfis (Figuras 4 e 5) predomina o quartzo, como mineral primário, de alto grau de estabilidade, muito resistente ao intemperismo (POPP, 1998). Quantidades expressivas de quartzo na fração areia dos horizontes latossólicos são indicadas pelos reflexos a 0,42 e 0,33 nm com pequena largura a meia altura e elevado grau de cristalinidade. Também foram encontrados picos de hematita, hematita/magnetita e caulinita no perfil 1 e picos de hematita, hematita/magnetita no Perfil 2.

De modo geral constata-se que a constituição mineralógica das frações dos solos estudados é evoluída e corresponde ao material de origem (basalto). Os solos estudados apresentam horizontes de elevado grau de intemperismo $(\mathrm{Bw})$. As assembleias mineralógicas desses solos indicam que eles se encontram em estágios de evolução mineralógica, isto é, são solos ferruginosos.

\section{Discussão dos resultados}

Através das análises desenvolvidas é possível apontar que na paisagem local, considerando os atributos pedológicos e geomorfológicos ocorre predomínio de pedogênese sobre a morfogênese, pois são encontrados em áreas de topo e médias vertentes solos espessos e bem desenvolvidos mineralogicamente. Evolutivamente, a paisagem sobre ocorrência dos solos estudados, por conta dos atributos encontrados no solo, teve sua formação relacionada a pedogênese sobre morfogênese. A geomorfologia local é apresentada pelo predomínio de áreas suave onduladas, com vertentes alongadas, convexas retilíneas permitindo uma boa infiltração da água, percolação desta no sistema solo, propiciando seu desenvolvimento pedológico.

Uberti e Klamt (1984) em estudos realizados fazendo correlações de solos com superfícies geomórficas enfatizam que a declividade do relevo está relacionada à intensidade do intemperismo. Curi e Franzmeier (1984) encontraram solos mais oxídicos em posições de relevo mais de topos e menos intemperizados em áreas com declives (CAMPOS, 2012).

Vidal Torrado e Lepsch (1999) relacionam áreas de superfícies geomorfológicas estáveis a desenvolvimento e estabilidade dos solos. Assim as ocorrências dos Latossolos em áreas mais de topo e muito bem desenvolvidas estão em concordância com a paisagem local (CAMPOS, 2012).

O perfil 1, sobre área de floresta, exemplo de condições naturais dessa classe de solo, apresenta valores semelhantes aos encontrados em solos da região (EMBRAPA, 1984; GHIDIN et al, 2006;) que ressaltam a inerente resistência desse solo a erosão e o estágio de evolução, já atingindo um nível de maturidade e estabilidade de solos evoluídos. Este grau de maturidade é também refletido pelos atributos químicos desses solos que, apresentam argilas de baixa capacidade de troca de cátions (gibbsita, caulinita e óxidos) e elevados teores de sexquióxidos de ferro e de alumínio e óxidos de titânio e manganês.

A textura muito argilosa dos Latossolos Vermelhos estudados (Tabela 1)evidencia intensa alteração sofrida pelo material de origem, assim como encontrado e citado por Guidin et al. (2006a). Além disso, elevados teores de silte, também foram citados por Ghidin et al. (2006a) que encontraram teores semelhantes em Latossolos Vermelhos Distroférricos em Cascavel (PR), no Qual discutiram sobre estes teores serem encontrados também em outras áreas em comuns, na região Sul do Brasil. Esses últimos discutiram que tais teores são maiores que alguns encontrados em outras áreas do sul Brasil por Netto (1996), também formados a partir do basalto e que estaria relacionado: (i) pela posição na paisagem (média e baixa vertente), caso que não se aplica aos solos aqui estudados, pois foram amostrados em situação de topo; (ii) ineficiência do método de dispersão para solos com altos teores de óxidos de Fe e Al.

A caulinita na fração argila de ambos os perfis apresenta picos $(001,002,003)$ típicos, com diferentes ordens e valores de espaçamento interplanar correspondendo, respectivamente a 0,716;0,358;0,239 nm. Em ambos os perfis, as amostras com tratamento a $\mathrm{K} 550^{\circ}$, o pico desaparece, corroborando com a inferência da existência de caulinita. (MELO; WYPYCH, 2009), como observado nos difratogramas.

A fração silte também apresentou semelhança entre e intra perfis. Essa fração é composta por minerais primários (quartzo), minerais secundários (caulinita) e óxidos de ferro (hematita; hematita/magnetita) e óxidos de titânio (anatásio e rutilo) e correspondem a minerais encontrados em ambientes de elevada intemperização (Figuras 4 e 5).

A presença da Caulinita predominando na fração argila corrobora o elevado grau de evolução dos solos estudados, pois este argilomineral é mais abundantes em solos de climas quentes e úmidos onde ocorre a perda parcial da sílica, o que permite a ocorrência da monossialitização, sendo condição favorável a formação e estabilidade desse argilomineral 1:1 no solo (DIXON1977; KAMPF et al., 2009;2012). 
A assembleia mineralógica dos solos estudados vem ao encontro da literatura corrente sobre a classe dos Latossolos Vermelhos, provenientes do basalto, que aponta o predomínio de argilominerais como a caulinita, gibbsita, goethita e hematita na fração argila (RESENDE, 1976; CURI, 1983; SANTANA, 1984; RESENDE et al., 1988; KER, 1995; BOGNOLA, 1996; KER, 1997; MELO et al., 2001a, b; GHIDIN et al.; 2006; SCHAEFER et al., 2008).

Estudos já realizados na região oeste do Paraná (MORESCO, 2007; MAGALHÃES, 2013; CALEGARI; MARCOLIN, 2014) confirmam a ocorrência dos Latossolos em área de relevo plano à suave ondulado, ocupando os setores de topo e média alta vertente no oeste paranaense.

\section{Conclusões}

Considerando os dados levantados e aos resultados obtidos afirma-se que:

Os Latossolo Vermelhos estudados estão em concordância com a paisagem local, ocorrendo nas áreas de topos mais planos e alongados, sob clima subtropical, com altas precipitações. Os atributos mineralógicos identificados nos dois perfis latossólicos estudados apresentam-se em concordância, em relação aos minerais identificados, com o material de origem (basalto) e estão de acordo com o grau de intemperização destes solos (ocorrência de minerais 1:1). São perfis de solos que representam a unidade de paisagem local, com a ocorrência de solos profundos e intemperizados.

Sobre os atributos pedológicos e geomorfológicos ocorre predomínio de pedogênese sobre a morfogênese. A geomorfologia local é apresentada pelo predomínio de áreas suave onduladas, com vertentes alongadas, convexas retilíneas permitindo uma boa infiltração da água, percolação desta no sistema solo, propiciando seu desenvolvimento pedológico, estando a unidade de paisagem integrada, com o sistema pedológico acompanhando o sistema geomorfológico.

\section{Referências}

AZEVEDO, A. C. \& VIDAL-TORRADO, P. Esmectita, vermiculita, minerais com hidróxi entrecamadas e clorita. In: Melo, V.F.; Alleoni, L.R.F. (Ed.). Química e mineralogia do solo: Parte I - Conceitos básicos. Viçosa: Sociedade Brasileira de Ciência do Solo, cap. 6, p. 381-426, 2009.

BECKER, E. L. S.; BURIOL, G. A.; STRECK, N. A. Clima e Intemperismo na Formação dos Solos do Rio Grande do Sul, Brasil. Revista Brasileira de Geografia Física 01 (2012) 33-46, 2012.

BOUTTON, T. W. Stable carbon isotope ratios of soil organic matter and their use as indicators of vegetation and climate change. In "Mass Spectrometry of Soils" (T. W. Boutton and S. Yamasaki, Eds.), pp. 47-82. Dekker, New York. (1996).

BROW G.; Brindley G.W. Crystal Structures of Clay Minerals and their X-ray Identification.MineralogicalSociety, 41 Queen's Gate, London SW7 5HR, 495 p. 1980.

CALEGARI, M. R. \&MARCOLIN, L. Relação Solo - Paisagem na Bacia da Sanga Matilde Cuê, Marechal Cândido Rondon (Pr). Boletim de Geografia. Maringá, v. 32, n. 3, p. 110-121. 2014.

CAMARGO, O.A.; MONIZ, A.C.; JORGE, J.A.; VALADARES, J.M.A.S. Métodos de Análise Química, Mineralógica e Física de Solos do Instituto Agronômico de Campinas. Campinas, Instituto Agronômico, 2009. 77 p. (Boletim técnico, 106, Edição revista e atualizada).

CAMPOS, M. C.C.; CARDOZO, N. P.; MARQUES JÚNIOR, J. Modelos de paisagem e sua utilização em levantamentos pedológicos. Revista de Biologia e Ciências da Terra. Vol. 6. № 1.p. 104-114. 2006.

CAMPOS, M. C. Relações solo-paisagem: conceitos, evolução e aplicações. Revista Ambiência. V. 8. No 3. p. $963-982.2012$.

CAVIGLIONE, J. H; KIIHL, L. R. B.; CARAMORI, P. H.; OLIVEIRA, D. Cartas climáticas do Paraná. Londrina: IAPAR, 2000. 
CURI, N. Lithosequence and toposequence of Oxisols from Goias and Minas Gerais States, Brazil. West Lafayette, Purdue University.158p. (Tese de Doutorado). 1983.

CURI, N.; FRANZMEIER, D.P. Topossequence of Oxisols from Central Plateau of Brazil.Soil Science Society American Journal.V. 48. p. 341-346. 1984.

DANIELS, R.B.; GAMBLE, E.F.; CADY, J.G.The relation between geomorphology and soil morphology and genesis. Adv.Agron., 23: 51-87, 1971.

DENT, D; HARTEMINK, A; KIMBLE, J. Soil: Earth skin. 16p. 2007. Disponível em: http://www.yearofplanetearth.org/. Consultado em 24/02/2015.

DIXON J.B. Kaolinite and serpentine group minerals.In: Minerals in Soil Environments (J.B. Dixon and S.B. Weed, editors). Soil Science Society of America, Madison, U.S.A, p. 357-403. 1977.

EMPRESA BRASILEIRA DE PESQUISA AGROPECUÁRIA.CENTRO NACIONAL DE PESQUISA DE SOLOS. Sistema brasileiro de classificação de solos. Brasília: Embrapa Produção de Informação. 353 p. 2013.

EMPRESA BRASILEIRA DE PESQUISA AGROPECUÁRIA.CENTRO NACIONAL DE PESQUISA DE SOLOS. Sistema brasileiro de classificação de solos. Brasília: Embrapa Produção de Informação. 353 p. 2018.

EMPRESA BRASILEIRA DE PESQUISA AGROPECUÁRIA - EMBRAPA. Solos do Estado de Santa Catarina. Boletim de Pesquisa e Desenvolvimento Nº 46. ISSN 1678-0892, 2004.

EMPRESA BRASILEIRA DE PESQUISA AGROPECUÁRIA.Manual de métodos de análise de solo. $2^{\mathrm{a}}$ edição, Rio de janeiro, 1997. 212p.

EMPRESA BRASILEIRA DE PESQUISA AGROPECUÁRIA.Serviço Nacional de Levantamento e Conservação de Solos. Levantamento de Reconhecimento dos Solos do Estado do Paraná. Curitiba, EMBRAPA-SNLCS/SUDESUL/IAPAR, TOMO I, 791p. 1984.

FONTES, M. P. F; Intemperismo de rochas e minerais.p.171-206.In: KER, João Carlos; CURI, Nilton; SCHAEFER, Carlos Ernesto G.R; TORRADO, Pablo Vidal. Pedologia: Fundamentos. Viçosa, MG, SBCS, 343p. 2012.

GHIDIN, A. A.; MELO, V. F.; LIMA V. C.; LIMA, J. M. J. C.Topossequências de Latossolos originados de rochas basálticas no Paraná. I - Mineralogia da fração argila. Revista Brasileira de Ciência do Solo. 30: 293-306, 2006a.

KAMPF, N.; CURI, N. \& MARQUES, J.J. Óxidos de alumínio, silício, manganês e titânio. In: Melo, V.F. \&Alleoni, L.R.F., eds. Química e mineralogia do solo. Viçosa, MG, Sociedade Brasileira de Ciência do Solo, v.1. p.573-610. 2009.

KAMPF, N.; MARQUES, J. J.; CURI, N. IV- Mineralogia de solos brasileiros, p. 81-145.IN: Ker, J.C.; Curi, N.; Schaefer, C. E.G.R; Vidal-Torrado, P. V. Pedologia: Fundamentos. Viçosa, MG, SBCS, 343p. 2012.

KER, J. C. Mineralogia, sorção e dessorção de fosfato, magnetização e elementos traços de Latossolos do Brasil. Viçosa, MG, Universidade Federal de Viçosa (Tese de Doutorado). 181p. 1995.

KER, J. C.Latossolos do Brasil: uma revisão. Geonomos, 5(1):17-40, 1997.

MAGALHÃES, V. L.Gênese e evolução de sistemas pedológicos em unidades de paisagem do município de Marechal Cândido Rondon-PR.Maringá, PR 2013. 123 f. Tese (Doutorado em Geografia).

MELFI, A. J. \& PEDRO, G. Estudo geoquímico dos solos e formações superficiais do Brasil. Parte 1Caracterização e repartição dos principais tipos de evolução pedogeoquímica. Revista Brasileira Geociências, p. 271-286. 1977. 
MELO, V. F.; SINGH, B.; SCHAEFER, C.E.G.R.; NOVAIS, R.F. \&FONTES, M.P.F.Chemical and mineralogical properties of kaolinite-rich Brazilians oils. Soil Science Soc. Am. J, 65:1324-1333, 2001 a.

MELO, V. F.; FONTES, M.P.F.; NOVAIS, R.F.; SINGH, B. \&SCHAEFER, C.E.G.R. Características dos óxidos de ferro e de alumínio de diferentes classes de solos. Revista Brasileira de Ciência do Solo, 25:19$32,2001 b$.

MELO, V. F.; \& WYPYCH, F. Caulinita e Haloisita. In: Melo, V.F. \&Alleoni, L.R.F., eds. Química e mineralogia do solo: Conceitos básicos. Parte 1. Viçosa, MG, Sociedade Brasileira de Ciência do Solo, v.1. p.427-504, 2009.

MINEROPAR (Minerais do Paraná S/A). Projeto riquezas minerais: avaliação do potencial mineral e consultoria técnica no município de Marechal Cândido Rondon. Curitiba, (Relatório Final) 2001.

MINEROPAR, Minerais do Paraná. Atlas geomorfológico do Estado do Paraná: Escala base 1:250.000 modelos reduzidos 1500.00. Curitiba, Universidade Federal do Paraná, 2006.

MOORE, D.M; REYNOLDS, R.C. X-ray Diffraction and the Identification and Analysis of Clay Minerals, Oxford University Press, Oxford.1989.

MORESCO, M.D. Estudo de paisagem no município de Marechal Cândido Rondon-PR. Maringá. Dissertação (Mestrado em Geografia) -DGE/PGE/UEM. 2007.

NETTO, A. R. Influência da mineralogia da fração argila sobre propriedades físico químicas de solos brasileiros. Viçosa: - Universidade Federal de Viçosa. 144p. 1996.Dissertação (Mestrado).

POPP, J. H.Geologia geral.LTC- livros técnicos e científicos, 5ª edição. 376p, 1998.

QUEIROZ NETO, J.P. Geomorfologia e pedologia. Revista Brasileira de Geomorfologia. Volume 1, 5967, 2000.

RAUEN, M.J. Mineralogicalidentificationof a toposequenceofsoilsfrombasaltic rocks in theStateof Paraná, Brazil. Lafayette, - PurdueUniversity. 161p., 1980. Tese (M. S.)

RESENDE, M. Mineralogy, chemistry, morphology and geomorphology of some soils of the Central Plateau of Brazil.West Lafayette, Purdue University (Tese de Doutorado), 237p.1976.

RESENDE, M. \& SANTANA, D.P. Uso das relações $\mathrm{Ki}$ e $\mathrm{Kr}$ na estimativa da mineralogia para a classificação dos Latossolos. In: Reunião de classificação, correlação de solos e interpretação de aptidão agrícola, 3., Rio de Janeiro, 1988. Anais. Rio de Janeiro, Embrapa - SNLCS, SBCS, p.225-232. 1988.

RESENDE, M.; CURI, N.; KER, J.C.; REZENDE, S. B. Mineralogia de solos brasileiros: interpretações e aplicações. Editora UFLA. 192p. 2005.

SANTANA, D.P. Soilformation in a toposequenceofOxisolsfrom Patos deMinas region, Minas Gerais State, Brazil.West Lafayette, Purdue University, 129p. (Tese de Doutorado). 1984.

SANTOS, L. J. C.; OKA-FIORI, C.; CANALli, N. E.; FIORI, A. P.; SILVEIRA, C. T..; SILVA, J. M. F.Mapeamento da vulnerabilidade Geoambiental do estado do Paraná.Revista Brasileira de Geociências. 37(4): 812-820. 2007.

SANTOS, L. J. C.; OKA-FIORI, C.; CANALLI, N. E.; FIORI, A. P.; SILVEIRA, C. T..; SILVA, J. M. F.; ROSS, J. L. S. Mapeamento Geomorfológico do Estado do Paraná. Revista Brasileira de Geomorfologia Ano 7, no 2, p.03-12. 2006.

SANTOS, R. D.; SANTOS, H. G.; KER, J. C.; ANJOS, L. H. C.; SHIMIZU, S. H.. Manual de Descrição e Coleta de Solos no Campo. SBCS. 102p.2015. 
SCHAEFER, C.E.G.R.; FABRIS, J.D. \& KER, J.C. Minerals in the clay fraction of Brazilian Latosols (Oxisols): A review. Clay Miner., 43:137-154, 2008.

TRICART, J. The landforms of the humids, forests and savanas.Longman.London. 1972.

UBERTI, A.A.; KLAMT, E. Relações solos-superfícies geomórficas na encosta inferior do nordeste do Rio Grande do Sul. Revista Brasileira de Ciência do Solo. Campinas, V. 8. p. 229-234. 1984.

VIDAL-TORRADO, P.; LEPSCH, I.F .Relações material de origem/solo e pedogênese com uma sequência de solos predominantemente argilosos e latossólicos sobre psamitos na Depressão Periférica Paulista. Revista Brasileira de Ciência do Solo. Viçosa. V. 23. p. 357-369. 1999.

WALKLEY, A; BLACK, I. A. An examination of the Degtjareff method for determining soil organic matter and a proposed modification of the chromic acid titration method. Soil Sci., 37: 29-38. 1934. 